\title{
O PIBID como campo fértil para a prática do licenciado em Dança e a formação de sua identidade docente
}

\author{
PIBID as a fertile field for the practice of the graduate in Dance and the \\ formation of his teaching identity
}

\author{
Marisa Martins Lambert 1 \\ Ana Maria Rodriguez Costas (Ana Terra)2 \\ Carine Gusson Shimoura ${ }^{3}$ \\ Mayara Borges Carneiro Domingues ${ }^{4}$
}

\section{Resumo}

Este trabalho apresenta reflexões, a partir das experiências das autoras, licenciadas em Dança e ex-bolsistas do Programa Institucional de Bolsas de Iniciação à Docência (PIBID), Subprojeto Dança Unicamp, acerca da formação e desenvolvimento da identidade docente do futuro professor de Dança/Arte. Compreende-se aqui identidade como a visão do indivíduo sobre o ensino de Dança e sua percepção da área de conhecimento da Dança nos processos de mediação e no despertar do sensível e da criatividade. Para além, pretende-se discutir sobre a necessidade da ocupação dos Subprojetos PIBID por parte de estudantes de licenciatura, como forma de expansão da experiência prática de ensino e das ponderações a respeito das pesquisas em licenciatura para espaços fora da Universidade. Aborda-se a inserção do professor em formação no meio escolar com a premissa de proporcionar autonomia e confiança em seu fazer docente, estimulando a criação de metodologias/ferramentas próprias para as propostas pedagógicas em

\footnotetext{
1 Universidade Estadual de Campinas. Professora do Programa de Pós-Graduação em Artes da Cena e dos Cursos de Bacharelado e Licenciatura em Dança. ORCID: https://orcid.org/0000-0002-33926833 Contato: marisalambert@iar.unicamp.br

${ }^{2}$ Universidade Estadual de Campinas. Professora do Programa de Pós-Graduação em Artes da Cena e dos Cursos de Bacharelado e Licenciatura em Dança. ORCID: https:/ /orcid.org/0000-0002-40884838 Contato: anaterradanza@gmail,com

3 Bacharel e Licenciada em Dança pela Universidade Estadual de Campinas. Contato: carine_shimoura@hotmail.com

4 Bacharel e Licenciada em Dança pela Universidade Estadual de Campinas. Contato: maybcd@gmail.com
} 
Conceição | Conception

Revista do Programa de Pós-Graduação em Artes da

Cena, Universidade Estadual de Campinas

Performing Arts Graduate Program Journal, University of

Campinas

desenvolvimento. Resguardadas suas particularidades temáticas, este artigo integra um dossiê que pretende destrinchar algumas entre as inúmeras questões relacionadas à necessidade de expansão e continuidade dos cursos de Licenciatura em Dança.

Palavras-chave: Licenciatura em Dança. PIBID. Formação de professores. Identidade docente. Educação Básica.

\section{Abstract}

This work presents reflections, based on the experiences of the authors, graduates in Dance and former scholarship participants of the Institutional Program for Teaching Initiation (PIBID), integrating Unicamp's Dance Subproject, in relation to the formation and development of the teaching identity of the future Dance/Art teacher. It is understood here as identity the individual's vision about teaching Dance and their perception of Dance as an area of knowledge, be it in processes of mediation or in the awakening of the sensitive and the creative. In addition, it is intended to discuss the need for the occupation of PIBID Subprojects by undergraduate students, as a way of expanding practical teaching experience and a form to consider research in the teaching field for spaces outside the University. It addresses the insertion of the teacher in training in the school environment with the premise of providing autonomy and confidence in their teaching, stimulating the creation of their own methodologies / tools appropriate to the pedagogical proposals under development. Subject to its thematic particularities, this article includes a dossier that intends to unravel some of the numerous issues related to the need for expansion and continuity of the Teaching Degree in Dance.

Keywords: Dance Teaching Graduation Degree. PIBID. Teachers Formation. Dance Teachers Identity. Basic Educational Level.

Este artigo pretende abordar reflexões sobre o potencial do fazer docente despertado pelas vivências de duas ex-bolsistas do Subprojeto PIBID Dança ${ }^{5}$, da Universidade Estadual de Campinas (Unicamp), e discutir suas contribuições para a formação da identidade docente de cada autora, que atuaram como parceiras de trabalho. Desenvolvendo inquietações sobre o que é a docência e a formação de um docente, emergiram duas questões disparadoras, que geraram o tema a respeito da

\footnotetext{
${ }^{5}$ O Subprojeto PIBID Dança se desenvolveu entre os anos de 2014-2017 tendo contemplado ao todo, durante esse período, 21 bolsistas do Curso de Licenciatura em Dança. Fez parte do Projeto Institucional da Unicamp de Iniciação à Docência que abrigou propostas de 13 licenciaturas, sendo aprovado no edital PIBID da CAPES Nº 061/2013.
} 
Conceição | Conception

Revista do Programa de Pós-Graduação em Artes da

Cena, Universidade Estadual de Campinas

Performing Arts Graduate Program Journal, University of

Campinas

importância da manutenção do Programa Institucional de Bolsas de Iniciação à Docência (PIBID): 1. Como a trajetória acadêmica de um licenciado em Dança / Arte Educação pode potencializar um trabalho coletivo e criativo no ensino formal?; 2 . Como se dá a construção da identidade docente do licenciando em Dança / Arte Educação e como a experiência no PIBID pode contribuir para este processo?. Desta forma, serão destacadas a necessidade do fortalecimento do campo das artes como área de conhecimento, a ocupação de espaços de ensino por estudantes de Licenciatura em Dança e sobre a fundamental existência e manutenção do projeto PIBID, que contribui para a formação de docentes cada vez mais engajados na construção de um pensamento sobre corpo e movimento que dialoga com a educação formal no âmbito das artes, assim como com os alunos lá inseridos e suas particularidades corporais, artísticas e educacionais.

\section{Contextualização}

Com o intuito de fomentar a pesquisa docente, o PIBID, promovido pela Coordenação de Aperfeiçoamento de Pessoal de Nível Superior (CAPES), através de bolsas de incentivo de iniciação à docência, viabiliza o diálogo Universidade/ Ensino Formal por meio de parcerias com escolas de educação básica da rede pública de ensino, aprimorando a formação de professores e consequentemente elevando o nível da educação escolar pública do país. O projeto é desenvolvido por Instituições de Ensino Superior (IES), contemplando diferentes cursos de licenciatura e suas propostas didático-pedagógicas para a inserção do licenciando no meio profissional.

Na Unicamp, o Programa está implementado desde 2010, sob a coordenação geral dos professores doutores Guilherme do Val Toledo Prado ${ }^{6}$, Eliana Ayoub ${ }^{7}$ e

\footnotetext{
6 Professor Livre-Docente da Faculdade de Educação da Unicamp e coordenador do GEPEC - Grupo de Estudos e Pesquisas em Educação Continuada. Graduado em Pedagogia pela Universidade Estadual de Campinas (1987), Mestre em Metodologia de Ensino (1992) e Doutor em Linguística Aplicada - Ensino e Aprendizagem de Língua Materna (1999), além de Livre-Docente em Educação
} 
Conceição | Conception

Revista do Programa de Pós-Graduação em Artes da

Cena, Universidade Estadual de Campinas

Performing Arts Graduate Program Journal, University of

Campinas

Elaine Prodócimo ${ }^{8}$. No ano de 2014, é aprovado o Subprojeto PIBID Dança, coordenado pela Profa. Dra. Marisa Martins Lambert ${ }^{9}$, sob a prerrogativa da necessidade de ocupação dos espaços formais de ensino por parte de estudantes de Licenciatura em Dança, melhor preparados para trabalhar com conteúdos específicos desta linguagem. Na prática esse objetivo apoiou-se na proposição de facilitar a implantação do currículo de Arte/Dança proposto pela Secretaria da Educação do Estado de São Paulo para os anos iniciais do Ensino Fundamental, em escola da rede pública estadual. Desta forma, nos primeiros dois anos de atuação do Subprojeto 2014 e 2015 -, período de trabalho das autoras, foram firmadas parcerias com duas escolas estaduais de Campinas - SP, localizadas nos bairros de Barão Geraldo (E.E. Físico Sérgio Pereira Porto) e Real Parque (E. E. Professor Roque Magalhães de Barros), atendendo as turmas de $1^{\circ}$ ao $5^{\circ}$ ano, dentro da disciplina de Artes.

Para a realização deste trabalho, será abordada majoritariamente a experiência em conjunto das bolsistas na escola de Barão Geraldo, sob supervisão da professora mestre em Artes, Agda Cristina Brigatto10, em algumas turmas dos primeiros, segundos e terceiros anos.

\footnotetext{
Escolar (2015), todos pela mesma Universidade. Atual Coordenador Institucional PIBID Unicamp. Lattes: http:/ / lattes.cnpq.br/0440747965664499

${ }^{7}$ Docente da Faculdade de Educação da Unicamp e Vice-Líder do Laboratório de Estudos sobre Arte, Corpo e Educação - Laborarte (FE). Graduada em Licenciatura e Bacharelado em Educação Física pela Unicamp, mestre e doutora em Educação Física pela mesma Universidade. Atual Coordenadora de Gestão de Processos Educacionais PIBID Unicamp. Lattes: http:/ / lattes.cnpq.br/ 2470414774023261

8 Professora Livre-Docente da Unicamp. Mestre em Educação Especial (Educação do Indivíduo Especial) pela Universidade Federal de São Carlos (1994), Doutora em Educação Física pela Universidade Estadual de Campinas (2002) e Pós-doutorado pela Universidade de Murcia (2013). Atualmente é Coordenadora de Gestão de Processos Educacionais PIBID Unicamp. Lattes: http://lattes.cnpq.br/0911069054007202

9 Docente do Departamento de Artes Corporais da Unicamp, artista e pesquisadora da Dança. Doutora em Artes pela mesma Universidade; Especialista em Análise do Movimento pelo Laban/Bartenieff Institute of Movement Studies, N.Y.; Bacharel em Fine Arts (Concordia University, CA) e em Pedagogia (PUC, SP). Lattes:http:/ / lattes.cnpq.br/1537430023629975

10 Mestre em Arte educação, especialista em Novas Tecnologias na Educação, pela Faculdade de Educação da Universidade Estadual de Campinas - Unicamp, é Bacharel e Licenciada em Artes Visuais pelo Instituto de Artes da referida instituição. De 2008 à 2016 atuou como professora da disciplina de Arte na Rede Estadual lecionando para o Ensino Fundamental - Ciclo I da educação básica. Lattes: http:/ / lattes.cnpq.br/ 6410292193676994
} 
Conceição | Conception

Revista do Programa de Pós-Graduação em Artes da

Cena, Universidade Estadual de Campinas

Performing Arts Graduate Program Journal, University of

Campinas

\section{Desenvolvimento}

O ensino de Dança no contexto escolar se faz fundamental, não apenas por seu caráter sensível, mas por despertar no indivíduo potencialidades corporais, estimular a criatividade, a propriocepção e a expressividade. Como área de conhecimento, propõe diversas maneiras de vislumbrar seus conceitos e conteúdos, primando pelos processos intrínsecos ao seu ensino como a criação, comunicação e a ressignificação de vocabulários.

Fruto de um ensino historicamente generalista de Artes, onde as Artes Visuais e a Música sempre marcaram maior presença no ambiente escolar, provavelmente devido à herança educacional das culturas predominantes no Brasil, a formação específica de professores de Arte só passa a ter diretrizes a partir dos anos 1970 (Lei $n^{\circ} 5692 / 1971$ ), sendo que as quatro áreas artísticas (artes visuais, dança, música e teatro) só tem seu ensino regulamentado mais de vinte anos depois, com a Lei $n^{\circ}$ 9.394/1996 (a Lei de Diretrizes e Bases da Educação, LDB) e a consolidação dos Parâmetros Curriculares Nacionais (PCN). Contudo, até os dias atuais, o cenário do ensino de Artes continua se deparando com dificuldades, principalmente quando o foco se dirige à dança como componente curricular, área coberta, em geral, pela atuação de profissionais não formados em dança, cujo domínio específico na linguagem se apresenta superficial. Para ensinar dança no contexto escolar, é importante a vivência prévia (TADRA et al, 2012); e, não apenas vivenciá-la, como também compreendê-la como movimento corporal e, num contexto artístico, como uma manifestação expressiva.

Desta maneira, o curso de Licenciatura em Dança da Unicamp propõe uma formação que qualifique o licenciado para o trabalho tanto no âmbito do ensino quanto em outras áreas do trabalho educacional, seja em ambientes escolares ou não. Para isso, o Projeto Pedagógico do curso prevê uma formação integrada entre conteúdos artísticos, pedagógicos e de fundamentação, do bacharelado e da licenciatura, indo ao encontro do pensamento de que para se ensinar, prática e teoria 
Conceição | Conception

Revista do Programa de Pós-Graduação em Artes da

Cena, Universidade Estadual de Campinas

Performing Arts Graduate Program Journal, University of

Campinas

precisam ser experienciadas pelo professor. Durante a trajetória acadêmica, o aprendiz é estimulado a refletir constantemente sobre seus fazeres, tanto do ponto de vista artístico, quanto de futuro educador, além de ter disciplinas como o estágio, em que se coloca na posição de pesquisador, observador e finalmente, de docente, com práticas pontuais, que em grande parte procuram adaptar-se ao trabalho já desenvolvido no ambiente em que estão inseridos.

O Subprojeto do PIBID traz um outro olhar sobre o fazer docente, e requer uma outra postura do bolsista. No caso das experiências das autoras, foi possível notar maior aprofundamento em leituras e discussões que serviram de escopo para a elaboração de seus planejamentos de aula, para a escrita de trabalhos apresentados em Congressos (ABRACE - Associação Brasileira de Pesquisa e Pós-Graduação em Artes Cênicas e ENALIC - Encontro Nacional das Licenciaturas), bem como para o fazer diário da docência. Essa experiência trouxe consigo maior tranquilidade para lidar com o ambiente da sala de aula, e assim as participantes estarem mais seguras para desenvolver suas próprias ferramentas de aproximação e condução. $\mathrm{O}$ crescimento das bolsistas despertou confiança por parte da supervisora e da coordenadora para permitir maior independência na realização das atividades e, futuramente, na conclusão de um processo realizado ao longo do último semestre de atuação das bolsistas.

\section{Experiências no Subprojeto Dança}

O primeiro contato com o Subprojeto Dança se deu através da leitura e reflexão sobre o material do Estado de São Paulo, proposto para o ensino das artes foco em dança, dos Parâmetros Curriculares Nacionais e da Lei de Diretrizes e Bases da Educação Nacional (LDB), visando ampliar o entendimento do projeto proposto pela coordenadora do Subprojeto Dança, Profa. Dra. Marisa Martins Lambert. 
Conceição | Conception

Revista do Programa de Pós-Graduação em Artes da

Cena, Universidade Estadual de Campinas

Performing Arts Graduate Program Journal, University of

Campinas

Alguns textos ${ }^{11}$ base foram abordados com o objetivo de fundamentar teoricamente as bolsistas, e assim oferecer-lhes um vislumbre da pesquisa do corpo e movimento na educação infantil.

Já na escola, o primeiro contato trouxe à tona um choque de realidade, bem como a insegurança de assumir a docência, ainda que sob supervisão. Num primeiro momento, foram propostas intervenções pontuais das alunas bolsistas, elaborando pequenas ações, que de maneira breve e convidativa, trouxessem um olhar mais sensível das crianças sobre seus próprios corpos. A partir disto, foi possível traçar um perfil sobre a escola e seus alunos, que até então tinham pouco contato com questões específicas de Dança, motivo pelo qual a escola mostrava-se resistente, por exemplo, a experimentações corporais de caráter mais exploratórios e à ações que envolvessem outros ambientes que não a sala de aula, que propusessem uma dinâmica diferente da vivenciada diariamente. Para além, a fricção entre o funcionamento escolar e os desejos ou expectativas de ensino das bolsistas impulsionam diversas reflexões acerca da infância e do movimento, promoveram revisões de paradigmas sobre o corpo, a educação e a docência, que se mostraram pertinentes ao desenrolar das atividades, e que precisavam ser constantemente revisitados por sua inerência ao ambiente em que o Subprojeto estava inserido.

Em síntese, o primeiro ano de atuação das bolsistas consistiu em integrar e adaptar os objetivos do Subprojeto às necessidades da escola e dos alunos, um maior aprofundamento no entendimento do material proposto pela Secretaria de Educação e a prática de planejamentos das atividades pretendidas.

O segundo ano de ações das alunas bolsistas, na E. E. Físico Sérgio Pereira Porto, buscou efetivar algumas proposições: trabalhar acolhimento do Subprojeto pela comunidade escolar; refinar a postura das bolsistas como proponentes de um projeto docente (que é diferenciada em relação ao estágio proposto pela Licenciatura) e, principalmente, garantir a inserção da Dança no currículo de artes da

\footnotetext{
11 Vide as referências bibliográficas deste trabalho.
} 
Conceição | Conception

Revista do Programa de Pós-Graduação em Artes da

Cena, Universidade Estadual de Campinas

Performing Arts Graduate Program Journal, University of

Campinas

escola. Iniciativas para viabilizar o diálogo entre a escola e o Subprojeto Dança ficaram mais presentes, com o intuito de melhorar o desenvolvimento das propostas e dar continuidade ao trabalho iniciado no ano anterior. Em um relatório produzido do mês de março de 2015, são exemplificadas algumas dessas iniciativas, como a participação no ATPC (Aula de Trabalho Pedagógico Coletivo) da E.E. Físico Sérgio Pereira Porto, onde uma das bolsistas teve a oportunidade de apresentar o Projeto para a coordenação da escola e seus professores, abordando: o que é o Projeto PIBID, seus objetivos de aproximação dos estudantes de Licenciatura em Dança com a prática docente, as escolas parceiras e ações em cada um delas, as atividades realizadas pelo projeto fora de sala de aula - como a organização da "I Semana: A Dança e o Seu Ensino"12 e as apresentações oferecidas a todas as crianças da escola do Grupo DançAberta13, além de planos futuros em elaboração.

Para desenvolvimento da pesquisa em sala de aula as bolsistas, responsáveis pelo terceiro ano do fundamental I, propuseram um planejamento comum com a supervisora Agda Brigatto, no qual foi feito um intenso trabalho, durante o segundo semestre de 2015, envolvendo as artes plásticas e a dança. O processo criativo visava contemplar aprendizagens tanto no campo das artes quanto no campo do conteúdo programático pelo qual os alunos estavam transitando (neste momento, animais do Pantanal). A partir disso, foram elaboradas aulas prático-teóricas que discutiam, de forma lúdica, no caso das Artes Visuais, apreciação estética de vídeos e imagens, composição de cores, desenhos, etc, e, no caso da dança, desde o conhecimento anatômico, reconhecimento e sensibilização das partes do corpo, sobre o que é

\footnotetext{
12 Entre os dias 13 e 18 de outubro de 2014, ocorreu o evento organizado pela Coordenadora do Subprojeto Dança e bolsistas, no Departamento de Artes Corporais do Instituto de Artes da UNICAMP, visando promover oficinas e debates com artistas-educadores em dança de reconhecimento, compartilhamentos de experiências e palestras sobre a Dança e seu ensino, além de divulgação das ações realizadas pelas bolsistas em campo e do Subprojeto como um todo.

${ }^{13}$ O DançAberta integra o Grupo de Pesquisa em Dança e Educação Somática do IA da UNICAMP. É dirigido pela Prof. ${ }^{a}$ Dr. ${ }^{a}$ Julia Ziviani, que atua no Departamento de Artes Corporais da Universidade Estadual de Campinas.
} 
Conceição | Conception

Revista do Programa de Pós-Graduação em Artes da

Cena, Universidade Estadual de Campinas

Performing Arts Graduate Program Journal, University of

Campinas

movimento e dança, engajando posteriormente esses conhecimentos à exploração de movimentos relacionados às movimentações dos animais estudados.

Durante este processo, as bolsistas puderam assumir o papel docente em aulas dedicadas à Dança, galgadas não apenas no Material da Secretaria da Educação, mas também a partir de literaturas como "Creative Dance for All Ages" (GILBERT, 1992), “A criança é performer" (MACHADO, 2010), “Corpo Sensível: fazendo pulsar o coração da dança na cidade" (CARVALHO, 2008), e oficinas, ministradas por convidados (sobre temas como danças circulares e ensino de dança para crianças) e também pela coordenadora do Subprojeto, esta última abordando as práticas do método Laban/Bartenieff ${ }^{14}$.

\section{Identidade docente e criação de recursos metodológicos}

A Dança teve sua construção histórica embasada na transmissão de conhecimentos de maneira hierárquica, onde o professor (maitre) era o detentor do saber e o aluno o receptor destes conteúdos.

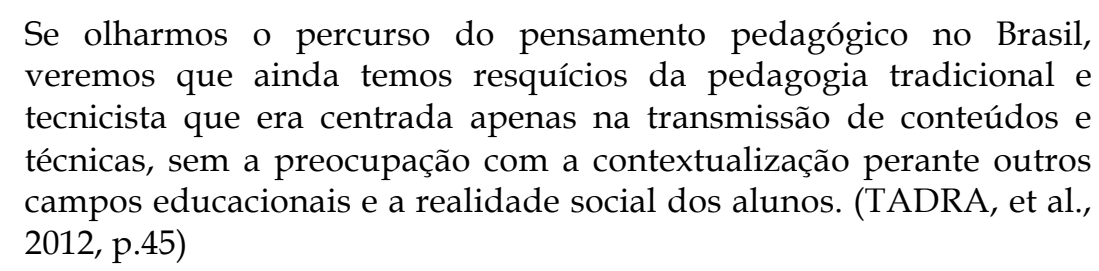

O ensino de dança como área de conhecimento nas escolas, pesquisas, fomentos culturais, e sua construção em ambientes formais é uma realidade que vem se transformando ao longo dos anos, com a criação de cursos certificativos/regulatórios e com a consolidação de cursos superiores em Dança. As licenciaturas estabelecem a formação de um profissional cada vez mais engajado em promover reflexões e discussões sobre o papel do docente na formação artístico-

\footnotetext{
${ }^{14}$ Método somático-expressivo que agrega os estudos sobre corpo e movimento de Rudolf von Laban (1879-1858), importante teórico e pedagogo da dança, precursor do entendimento do movimento como linguagem expressiva, e Irmgard Bartenieff (1900-1981), bailarina e fisioterapeuta, criadora do método somático "Fundamentos Corporais do Movimento".
} 
Conceição | Conception

Revista do Programa de Pós-Graduação em Artes da

Cena, Universidade Estadual de Campinas

Performing Arts Graduate Program Journal, University of

Campinas

pedagógica do aprendiz, e na construção de um pensamento crítico sobre a emancipação do corpo. Com isso, observa-se uma tendência de ensino preocupada em estabelecer uma relação professor-aluno mais sensível e construtiva, onde ambos aprendem com suas experiências.

Assim, a vivência no PIBID proporciona aos bolsistas a chance de exercer práticas educacionais favoráveis à pesquisa, desde o estudo do corpo da criança, firmado no pensamento de que ela é um ser artístico, inserido em um determinado ambiente e cuja história influencia a maneira como se relaciona com a sociedade e suas ações, além de suas movimentações e brincadeiras. O contato direto com outros formadores e a supervisão por parte do meio acadêmico e escolar, torna os docentes em formação mais confiantes, respaldados pela experiência de profissionais da área e, ao mesmo tempo, ativos em suas próprias ações, contribuindo na criação de conteúdos e planejamentos pedagógicos, exercícios fundamentais para fomentar uma formação docente ampla. $O$ ambiente educacional formal possui particularidades e desafios, principalmente tratando-se da transformação de estruturas rígidas, como a disposição de carteiras frente a lousa, em campo de livre movimentação e exploração nas aulas de Dança, o que demanda constante trabalho reflexivo e estratégias de ação. “Empilhar carteiras para se conseguir um espaço vazio é praticamente condição sine qua non para quem se propõe a ministrar aulas de dança e/ou de teatro na escola." (STRAZZACAPPA, 2008, p.03)

Em suas práticas no Subprojeto PIBID Dança, as autoras acreditam ter firmado novos caminhos a serem percorridos durante suas trajetórias posteriores à formação acadêmica, e que independente do ambiente educacional, se farão primordiais para a difusão deste ideal de construção de conhecimento em Dança, corpo e movimento. A seguir, serão exemplificadas algumas das ações que aconteceram durante o período de participação no PIBID e que apresentaram reflexos no fazer docente atual das bolsistas. 


\section{Conceição | Conception}

Revista do Programa de Pós-Graduação em Artes da

Cena, Universidade Estadual de Campinas

Performing Arts Graduate Program Journal, University of

Campinas

A "Caixinha das Sensações" foi um recurso utilizado para a memorização de ações aprendidas durantes as aulas de artes/dança; um armazenador imaginário no qual eram guardadas as sensações corporais novas de cada dia.

Todos os corpos são sensíveis? Sim, todos os corpos são sensíveis, no entanto, podem tornar-se mais ou menos sensíveis. Muitas sensações e sensibilidades podem ficar quase adormecidas, diminuindo a nossa capacidade expressiva e principalmente a capacidade de vivenciarmos as experiências com inteireza. Podemos chegar a viver como máquinas, cumprindo tarefas automaticamente [...]. (CARVALHO, 2008, p. 79)

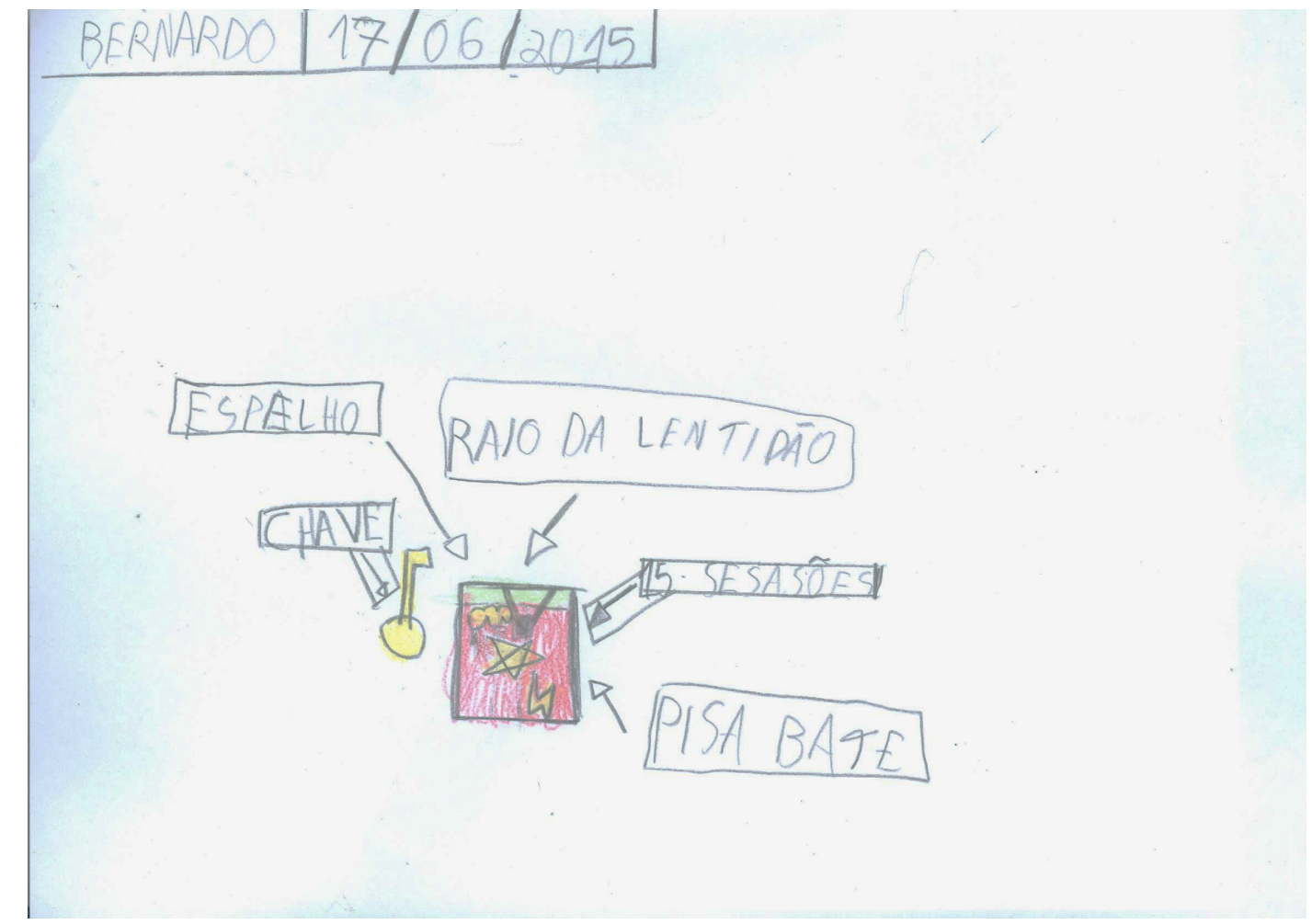

Imagem 1. Registro em desenho de um aluno do $2^{\circ}$ ano sobre a "Caixinha das Sensações".

Dentre essas ações estavam, “O Banho” - exercício de sensibilização corporal (percepção da pele, músculos, dos espaços articulares, ossos, de todo o contorno do corpo e do espaço pessoal), introdução à anatomia - de forma lúdica e sucinta, os alunos exploravam o corpo descobrindo cada parte dele. A exploração foi iniciada 
Conceição | Conception

Revista do Programa de Pós-Graduação em Artes da

Cena, Universidade Estadual de Campinas

Performing Arts Graduate Program Journal, University of

Campinas

partindo dos pés à cabeça, seus limites, sua forma, sua composição e as possibilidades de movimento.

Outra ação realizada pelas alunas, o "Raio da Lentidão", surgiu em um momento de insight, para agrupar os alunos e ter a atenção necessária para prosseguir a aula. Esse recurso modifica a qualidade corporal dos alunos, que são induzidos a desacelerar o ritmo, levando-os a um ambiente denso, muito lento, e à um estado corporal mais atento. Conforme sugere Agda Brigatto, sobre a criação de procedimentos no curso da ação de ensino-aprendizagem:

Esse processo não é objetivo e muito menos linear e exige do docente um olhar seletivo. Ao priorizar, intuitivamente, uma ação, outra é abandonada e essa seleção modifica todo o percurso do que será realizado. (BRIGATTO, 2014, p.35)

A transformação do pensamento sobre o corpo, que aconteceu durante o processo acadêmico (sabe-se agora que o corpo possui memórias, que não é vazio de conhecimento e experiência, que possui particularidades que podem ser estimuladas), suscitou mudanças na interpretação do que é a dança e o seu fazer artístico. Foram nos caminhos para descobrir este lugar, de pensar a dança para diferentes corpos e ideias, que a identidade docente começa a se manifestar, rodeada de questionamentos do atual cenário artístico/pedagógico.

\footnotetext{
Percebendo-se que o trabalho corporal não poderia chegar ao seu objetivo somente com a repetição de movimento, a dança foi à procura de caminhos que trouxessem a ela uma maior compreensão do corpo. [...] como objetivo principal a conscientização corporal, a dança se serviu delas para melhor desenvolver e utilizar o corpo e suas individualidades dentro do movimento. (TADRA, et al., 2012, p. 35)
}

Com projetos de incentivo à pesquisa docente, a licenciatura em dança passa a ter um caráter de representatividade na educação de artes/dança tanto no ensino formal, como não formal, ocupando os mais diversos ambientes.

Os reflexos atuais da trajetória acadêmica de um licenciando em arteeducação e das influências do Subprojeto PIBID Dança, levaram as ex-bolsistas a um caminho de muitas questões não respondidas, conscientes de que essas dúvidas 
Conceição | Conception

Revista do Programa de Pós-Graduação em Artes da

Cena, Universidade Estadual de Campinas

Performing Arts Graduate Program Journal, University of

Campinas

fazem com que o educador progrida em sua carreira, sem se deixar estagnar. É no fazer docente que ocorre a evolução e a infinita reciclagem de pensamentos, necessária para enfrentar os diversos obstáculos, imprevistos com os quais o meio da arte sempre se deparou. Percebe-se que as ferramentas utilizadas em sala de aula não são apenas as propostas feitas aos alunos (e que podem ser, assim como atualmente são, resgatadas para outros ambientes educacionais em que as autoras estiverem inseridas). Referem-se também ao modo como é construída a relação professor/aluno, propiciadora da troca de saberes; ao pensamento de que o aluno não é um recipiente vazio que precisa ser preenchido, e sim sujeito detentor de uma história/vivência e conhecimento; à liberdade de se permitir improvisar em situações que possam ser aproveitadas (como no caso do "raio da lentidão", em que se pode transformar uma situação partindo da necessidade dos alunos) e à importância do diálogo com as pessoas do ambiente de trabalho, para esclarecer propostas de trabalho e ter a possibilidade de troca de conhecimentos.

\section{Considerações Finais}

O ensino de Artes, e especificamente de Dança, nos ambientes formais de educação, é necessário para a compreensão total do ser. Promove o empoderamento do indivíduo sobre seu próprio corpo, motiva o desenvolvimento de outras linguagens, modos de expressão e vias de despertar do sensível. Estimula a criatividade, novas formas de construção de conhecimento que não considere apenas teoria, mas também corpo pensante. E é de grande urgência que seja feito por profissionais especializados, preocupados e atentos com os processos plurais e engajados na formação de uma sociedade cada vez mais consciente e crítica.

A dança, dentro do contexto social, é de grande importância como auxiliar na valorização de um pensamento crítico transformador, articulando a linguagem corporal com a verbal, conectando-as a conteúdos pedagógicos que garantam autoconhecimento e fortalecimento social. (TADRA, et al., 2012, p.49) 
Conceição | Conception

Revista do Programa de Pós-Graduação em Artes da

Cena, Universidade Estadual de Campinas

Performing Arts Graduate Program Journal, University of

Campinas

E para a formação destes profissionais, o caminho da Licenciatura se mostra cada vez mais necessário e carente de fortalecimento. Um professor-artista que possa ter a chance de participar de projetos como o PIBID, torna-se confiante para compartilhar experiências, adquiridas ao longo de sua trajetória acadêmica, em ambientes educacionais, apto a transitar entre meios formais e não formais, com a premissa de extrapolar correntes tradicionais de ensino ${ }^{15}$. Para além, cumpre papel de destaque na articulação de ensino e produção da Arte, protagonizando a criação de ferramentas e metodologias próprias que o auxiliam na mediação de processos criativos ou mesmo no cotidiano em sala de aula. Estas ações consolidam a eficiência da pesquisa docente como caminho para uma formação envolvida na democratização do ensino/pensamento de dança e sua ação transformadora.

\section{REFERÊNCIAS}

BRASIL. Lei $\mathbf{N}^{\circ} 5.692$ de 11 de agosto de 1971. Disponível em: http://www.camara.gov.br/sileg/integras/136683.pdf Acesso em 08 de nov. 2016.

BRASIL. Lei $\mathbf{n}^{\circ} \mathbf{9 . 3 9 4}$ de 20 de dezembro de 1996. Disponível em: https://www.planalto.gov.br/ccivil_03/Leis/L9394.htm Acesso em 08 de nov. 2016

BRASIL. Lei de Diretrizes e Bases da Educação Nacional. Disponível em: http://www.ufsj.edu.br/portal2-repositorio/File/proen/ldb_11ed.pdf Acesso em 08 de nov. 2016.

BRASIL. Ministério da Educação. Secretaria de Educação e Desportos. Parâmetros Curriculares Nacionais: Arte. Brasil, 1998.

BRIGATTO, A. Os caminhos do artista educador em busca de imagens significativas. 2014. 179 f. Dissertação (Mestrado em Educação, Conhecimento, Linguagem e Arte) - Faculdade de Educação, Universidade Estadual de Campinas, Campinas/SP, 2014.

15 Cabe dizer que no ano de 2016 o Programa de Iniciação à Docência esteve prestes a ser instinto pela CAPES, tendo conquistado sua continuidade, até final de 2017, devido a forte movimento de luta nacional de seus participantes - instituições universitárias públicas e privadas, escolas beneficiadas, coordenadores de projetos, supervisores e bolsistas. Atualmente, apesar de perdas em sua estrutura e concepção, iniciou-se o edital PIBID No 7/2018, em agosto desse ano, também como consequência de intensa pressão dos envolvidos. 
Conceição | Conception

Revista do Programa de Pós-Graduação em Artes da

Cena, Universidade Estadual de Campinas

Performing Arts Graduate Program Journal, University of

Campinas

CARVALHO, L. . Corpo Sensível: fazendo pulsar o coração da dança na cidade. In: ARAÚJO, E;CARVALHO, L; VILLARDI, F; SCHWINDEN, L; HELLENO, M. (Org.). Núcleo Vocacional: criação e trajetória. São Paulo: , 2008, p. 77 - 83.

CAPES - Coordenação de Aperfeiçoamento de Pessoal de Nível Superior. PIBID Programa Institucional de Bolsas de Iniciação à Docência. Disponível em <http://www.capes.gov.br/educacao-basica/capespibid/pibid> Acesso em: 24 nov. 2016.

COMVEST. Curso de Dança. Disponível em <http://www.comvest.unicamp.br/cursos/danca.html> Acesso em 06 nov. 2016.

FACULDADE DE EDUCAÇÃO da Universidade Estadual de Campinas. PIBID UNICAMP. Disponível em: <https://www.fe.unicamp.br/graduacao/programasinstitucionais/pibid-programa-institucional-de-bolsas-de-iniciacao-a-docencia> Acesso em: 24 nov. 2016

GILBERT, A. G. Creative Dance for All Ages. United States, Champaign, IL: Human Kinetics, 1992.

LABAN, R. Domínio do Movimento. São Paulo: Summus, 1978.

MACHADO, M. M. A criança é performer. Performance, Performatividade e Educação. v. 35, n.2, maio/agosto, 2010, p. 115 - 137. Disponível em: < http://seer.ufrgs.br/index.php/educacaoerealidade/article/view/11444/9447 > Acesso em 06 de nov. 2016

MORANDI, C., STRAZZACAPPA, M. Entre a Arte e a Docência: a formação do Artista da Dança. Campinas, SP: Papirus, 2006. (Coleção Ágeres)

TADRA, A. et al. ORTOLAN, S. M.(Org) Linguagem da Dança. Curitiba: InterSaberes, 2012. (Coleção Metodologia do Ensino de Artes)

UNICAMP. Grupo DançAberta. Disponível em: < <http://www.unicamp.br/unicamp/noticias/2015/09/04/dancaberta-do-instituto-deartes-estreia-o-espetaculo-des-equilibrando-avessos> 